\title{
Utilization of Scanning Electron Microscopy to Optimize Electroless Deposition of Pd Thin Film on Porous Stainless Steel
}

\author{
B. S. Mpofu ${ }^{1}$, W. E. Goosen ${ }^{2}$, J. Kurehwatira ${ }^{1}$, M. J. Myers ${ }^{1}$, K. Munjeri ${ }^{1}$, and T. Gutu ${ }^{1}$ \\ 1. Department of Physics, University of Zimbabwe, Harare, Zimbabwe. \\ 2. Centre for High Resolution Transmission Electron Microscopy, Nelson Mandela Metropolitan \\ University, Port Elizabeth, South Africa.
}

Electroless deposition of platinum group metals is a technologically attractive coating technique due to its flexibility, low cost, ease of operation and control, and ability to uniformly coat complex shapes. For instance, $\mathrm{Pd}$ and $\mathrm{Pd}$-based thin films have wide applications in $\mathrm{H}_{2}$ permselective membranes, gas sensors and catalysis [1]. Pd-based membranes for $\mathrm{H}_{2}$ separation and purification require deposition of thin defect-free metallic film on a porous support such as stainless steel or alumina for higher $\mathrm{H}_{2}$ flux and low cost. However, deposition of defect-free thin Pd film still remains a technological challenge. The microstructure of the electroless-deposited film depends on the electroless bath chemistry as well as deposition parameters [2]. Thus, this investigation aims to optimize the concentration of the precursor in the electroless deposition of Pd film.

In order to facilitate electroless deposition, the porous stainless steel supports were thoroughly cleaned before surface activation by seeding with Pd nuclei using a dip coating technique. $\mathrm{PdCl}_{2}$ and hydrazine were used as the source of $\mathrm{Pd}$ and reducing agent during the electroless deposition process. The bath temperature was about $60{ }^{\circ} \mathrm{C}$. Morphological analysis of as-prepared $\mathrm{Pd}$ thin films was carried out using a JEOL JSM 7001F FEGSEM equipped with an EDS spectrometer for elemental composition analysis. The analysis was conducted at a working distance of about $5 \mathrm{~mm}$ and an acceleration voltage of $10 \mathrm{kV}$.

Figure 1 shows the SEM results of the optimization with respect to $\mathrm{PdCl}_{2}$ concentration of electroless deposition of Pd onto porous stainless steel (PSS). Pd metallic particles appear as white or greyish dots against a dark background of PSS in the SEM micrographs in Fig. 1. The results indicate that support surface coverage by $\mathrm{Pd}$ metal increased with decreasing precursor (i.e. $\mathrm{PdCl}_{2}$ ) concentration till complete coverage was attained and then the coverage started decreasing with decreasing precursor concentration. At a high concentration of $24 \mathrm{~g} / \mathrm{L}$ the coverage was less than $10 \%$ (Fig. 1a); at $16 \mathrm{~g} / \mathrm{L}$ the coverage was more than $50 \%$ (Fig. $1 \mathrm{~b}$ ), and at $4 \mathrm{~g} / \mathrm{L}$ the coverage was conformal, continuous and complete. At concentration below $0.5 \mathrm{~g} / \mathrm{L}$ the support coverage was incomplete (Fig. 1d). EDS elemental analysis was used to confirm the presence of Pd as shown in Fig. 2. The mean Pd particle size and size distribution decreased with decreasing precursor as measured by the SEM. Fig. 1a-b show discrete Pd particles with a wide size distribution. However, continuous films present a great challenge in measuring the particle sizes due to coalescence (Fig. 1c-d). To conclude, this study revealed that a uniform, continuous and complete Pd thin film can be electrolessly deposited onto a PSS support when the $\mathrm{PdCl}_{2}$ concentration is between $4 \mathrm{~g} / \mathrm{L}$ and $0.5 \mathrm{~g} / \mathrm{L}$ under the experimental conditions.

References:

[1] S Liguori et al, Membranes 4, (2014), 143-162.

[2] Y S Cheng et al, Journal of Membrane Science 182 (2001), 195-203. 
[3] Authors acknowledge funding from the University of Zimbabwe Research Board grant No: RB36 and The World Academy of Sciences research grant agreement No: 14-108 RG/PHYS/AF/AC_I-

UNESCO FR: 324028571. The electron microscopy analysis was done at Nelson Mandela Metropolitan University's Centre for High Resolution Transmission Electron Microscope
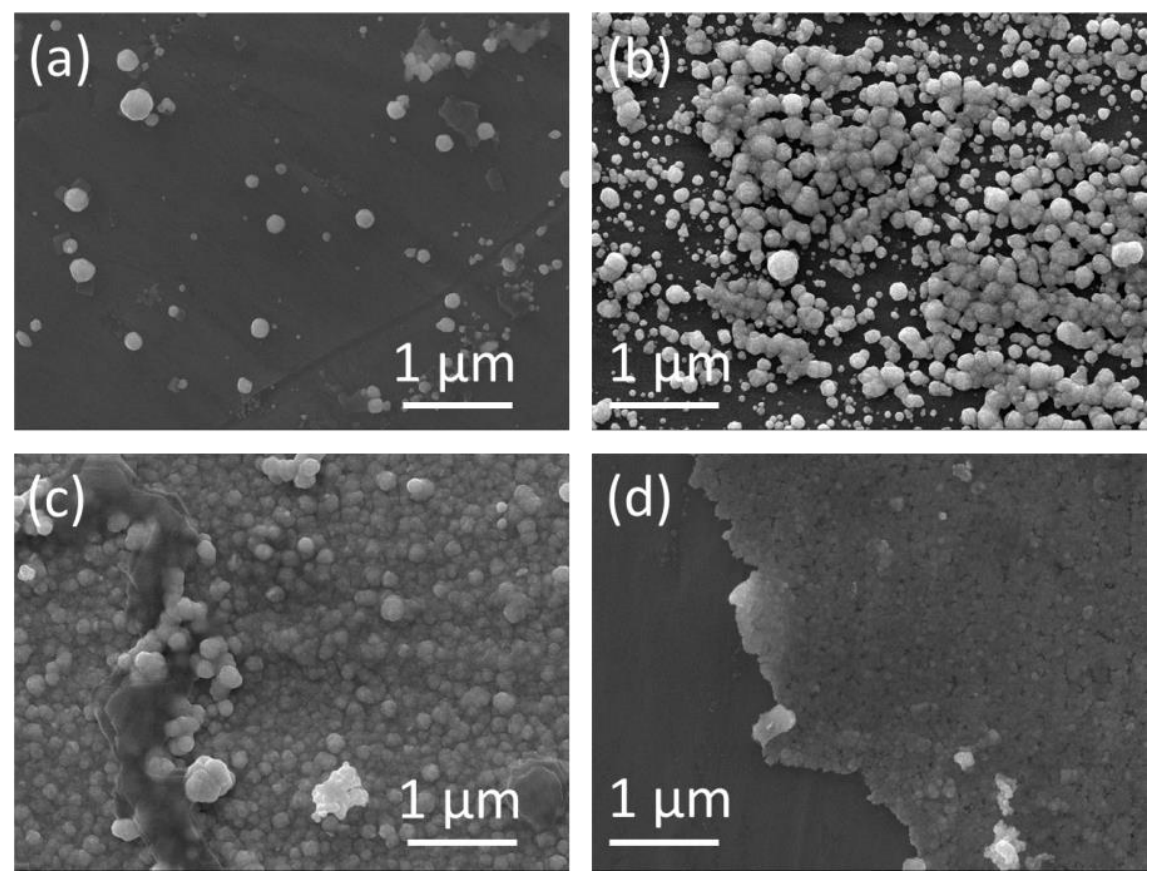

Figure 1. SEM micrographs revealing the optimization of electroless deposition of Pd with respect to $\mathrm{PdCl}_{2}$ concentration: (a) $24 \mathrm{~g} / \mathrm{L}$, (b) $16 \mathrm{~g} / \mathrm{L}$, (c) $4 \mathrm{~g} / \mathrm{L}$, and (d) $0.225 \mathrm{~g} / \mathrm{L}$.

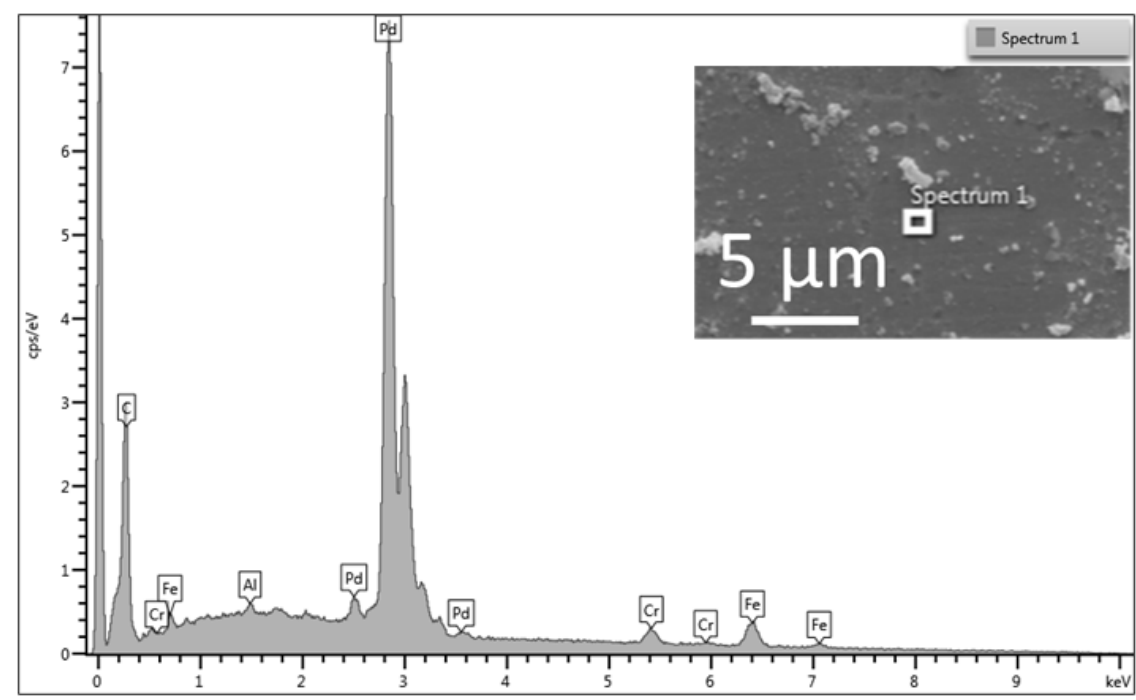

Figure 2. EDS spectrum showing the presence of Pd in the thin film deposited on porous stainless steel. The insert shows the SEM micrograph indicating the actual area where the spectrum was taken. 